\title{
When and How Do We Need Permission to Help Patients Address Social Risk?
}

\author{
Jennifer E. DeVoe, MD, DPhil
}

( J Am Board Fam Med 2020;33:176-178.)

Amid mounting evidence that health care services have a relatively small impact on health outcomes, which is dwarfed by the influences of a patient's social context, many health care institutions are clamoring to learn more about their patients' social risks. Increasing numbers of clinics, hospitals, and emergency departments are now administering social risk screening questionnaires or asking about the social, economic, and behavioral risk factors of their patients in other ways. ${ }^{1,2}$ In their commentary in this issue, De Marchis et al (2020) describe the rapid proliferation of these efforts, supported by national recommendations from esteemed organizations, such as the National Academies of Science, Engineering and Medicine, to continue doing so. ${ }^{1,3}$ These efforts are being undertaken to more clearly identify subsets of vulnerable patients who have social risk factors that can be addressed by health care providers through various means (eg, referrals to social service agencies, increased intensity of care management services, embedding behavioral health providers into clinics and hospitals, food pantries, enhanced child care, and transportation offerings). In turn, these interventions to address patients' heightened social risks might result in shorter hospital stays, less frequent emergency department visits, reductions in preventable readmissions, and improved overall health of patient populations for which a system is accountable (and for whom the

Funding: None.

Conflict of interest: No conflicts of interest or competing interests to disclose.

Corresponding author: Jennifer E. DeVoe, MD, DPhil, Department of Family Medicine, Oregon Health \& Science University, 3181 Sam Jackson Park Rd, FM, Portland, OR 97239 (E-mail: devoej@ohsu.edu).

See Related Article on Page 170. system is likely assuming some financial risk). De Marchis et al (2020) shine a spotlight on an interesting paradox that is emerging in this flurry of activity: although patients are often willing to report social risks to their health care providers, many patients do not want help in addressing them. ${ }^{1}$

Does this mean that health care systems should stop screening patients and/or defund programs designed to help patients address social risks? Well, given the irrefutable evidence about the huge impact social context has on health, any health care system leaders deciding to take this type of action would be pushing their heads further into the sand. Instead, De Marchis et al (2020) astutely and persuasively call for more research into several aspects of this complex area, which could better inform appropriate action. ${ }^{1}$ Research is needed to improve our screening approaches and the precision of our diagnostic capabilities and to determine the best methods for getting help to those who need it the most. ${ }^{4,5} \mathrm{We}$ could also be developing a more robust scientific agenda to build the evidence that supports how best to more appropriately develop and tailor our efforts. For example, if systems have limited resources, they may want to implement and test mechanisms for determining which patients are more or less likely to report social risk information or predicting which patients are most likely to accept and benefit from the help being offered. Alternatively, maybe systems could universally screen all patients with a short survey and reserve a longer survey and other more intensive investment only if patients want assistance. This approach, unfortunately, could exacerbate health disparities, as it might be more likely to help those patients with fewer needs and, thus, divert resources away from patients with more needs or greater deprivation. ${ }^{6}$ Thus, some systems might want to know whether it is effective to target enhanced assistance efforts toward patients 
believed to be at highest risk based on what is known about their neighborhood context, a "community vital signs" approach. ${ }^{7,8}$

Another area for further investigation pertains to whether health care teams should be investing more time and energy into designing effective interventions to encourage all patients to accept help. Would there be benefit to implementing effective educational approaches that teach patients about the direct impact that toxic stress and adverse experiences have on their health? What patientcentered implementation strategies could be used for social risk screening and interventions to increase patient acceptability? Moving forward in this direction would ideally require sound evidence that addressing social risk factors in health care settings is causally linked to improved health outcomes. ${ }^{4}$ Some would argue that taking these types of actions would be premature, given the paucity of effective screening instruments, diagnostic tests, and treatment approaches. They would say "we need to do something; however, we do not yet know what to do, so we should wait." Others would exert that the evidence is clear regarding the link between social context and health, and it is imperative that some action be taken now. In other words "We need to do something now; waiting for "more research' is denying that a problem exists."

As a first step in many of these future investigations, it is important to know why patients are not interested in accepting help from their primary care teams or their health care institutions. De Marchis et al (2020) present a review of many of the most plausible explanations. They present early evidence to suggest that there are some important factors likely influencing rates of accepting help, as rates do vary widely. One could hypothesize that a trusting relationship with a primary care team might be associated with higher rates of accepting help. On the other hand, a patient might be ashamed to reveal their social vulnerabilities to a revered person known to them and feel more comfortable asking for help from a stranger. Or, it might simply be an issue of not having enough time to fill out the form. Another related question to answer is when patients report that they do not want help, what does this mean? Does it mean they truly do not desire help or believe they would benefit from help? Or, does it mean that they do not expect their clinician to help, they do not want to explicitly be seen as needing help, or that they do not believe their health care teams can help? There are likely numerous reasons for why patients may not want help. Some may feel defeated by the "system" or overwhelmed by the multiple hoops through which a person must jump to get help. They may have had a negative experience with receiving a needed service that was not sustained. Some may be concerned about their immigration status or the status of family members.

As these academic debates continue, help is being provided to patients and communities on a daily basis by family medicine teams without a standardized survey or an explicit request for permission. Decades before there were social risk screening tools embedded within electronic health records or surveys being administered in waiting rooms, family doctors and many others on the team have been aware of the social, economic, and behavioral factors impacting their patients' health and actively incorporating into their day-to-day practice numerous strategies and services to help. The dedication, compassion, and healing presence of primary care teams in communities enables many patients to share painful stories about trauma and adverse experiences. ${ }^{9}$ Primary care clinics that nurture and value patient-clinician continuity are safe spaces for patients to share some of their most intimate thoughts and fears. ${ }^{10}$ Patients and families have been sharing this information-in spoken and unspoken ways-with their care teams for centuries; and primary care clinicians have been acting on this information every day-sometimes explicitly but often implicitly in ways that patients may not even be aware. It is woven into the fabric of our professional work, our relationships, and what we do every day. Some people do it naturally and it is almost second nature. Others are less comfortable or familiar with how to do it but still find themselves venturing into this space whenever they instinctively sense the need and feel compelled to help.

Should we stop offering this help unless we receive permission to do so? I think we should carry on doing it and seek evidence that enables us to do more of it and to get better at it. I also think it is important to recognize that many patients do not expect us to fix these problems and may not even want (or need) our help. We can improve our ability to more consistently and comprehensively recognize all social factors impacting each and every patient's health and to recognize when patients 
want and need our help most. Also, we can continue to build an evidence base to know when and how to do this important work most effectively.

I am grateful to the many colleagues and patients who have taught me so much about the impact of social, economic, and behavioral factors on health.

To see this article online, please go to: http://jabfm.org/content/ 33/2/176.full.

\section{References}

1. De Marchis EH, Alderwick H, Gottlieb LM. Do patients want help addressing social risks? J Am Board Fam Med. In press.

2. Tong ST, Liaw WR, Kashiri PL, et al. Clinician experiences with screening for social needs in primary care. J Am Board Fam Med. 2018;31: 351-63.

3. National Academies of Sciences, Engineering, and Medicine. Integrating social care into the delivery of health care: moving upstream to improve the nation's health. Washington, DC: National Academies Press; 2019.

4. Krist AH, Davidson KW, Ngo-Metzger Q. What evidence do we need before recommending routine screening for social determinants of health? Am Fam Physician. 2019;99:602-5.

5. DeVoe JE, Bazemore AW, Cottrell EK, et al. Perspectives in primary care: a conceptual framework and path for integrating social determinants into primary care practice. Ann Fam Med, 2016; 14:104-8.

6. Gottlieb LM, Alderwick H. Integrating social and medical care: could it worsen health and increase inequity? Ann Fam Med. 2019;17:77-81.

7. Hughes LS, Phillips RL, Jr., DeVoe JE, Bazemore AW. Community vital signs: taking the pulse of the community while caring for patients. J Am Board Fam Med. 2016;29:419-22.

8. Bazemore AW, Cottrell EK, Gold R, et al. "Community vital signs": incorporating geocoded social determinants into electronic records to promote patient and population health. J Am Med Inform Assoc. 2016;23:407-12.

9. Scott JG, Cohen D, Dicicco-Bloom B, Miller WL, Stange KC, Crabtree BF. Understanding healing relationships in primary care. Ann Fam Med. 2008;6:315-22.

10. Mainous AG, 3rd, Goodwin MA, Stange KC. Patient-physician shared experiences and value patients place on continuity of care. Ann Fam Med. 2004;2:452-4. 